\title{
25. Repetition using PERFORM..UNTIL
}

The computer can be instructed to repeat a paragraph - or a group of paragraphs until a certain condition is true.

e.g. PERFORM PROCESS-STUDENT-INFO UNTIL STUDENT-NO > 9

The computer will carry out paragraph PROCESS-STUDENT-INFO as long as STUDENT-NO is not greater than 9.

Example

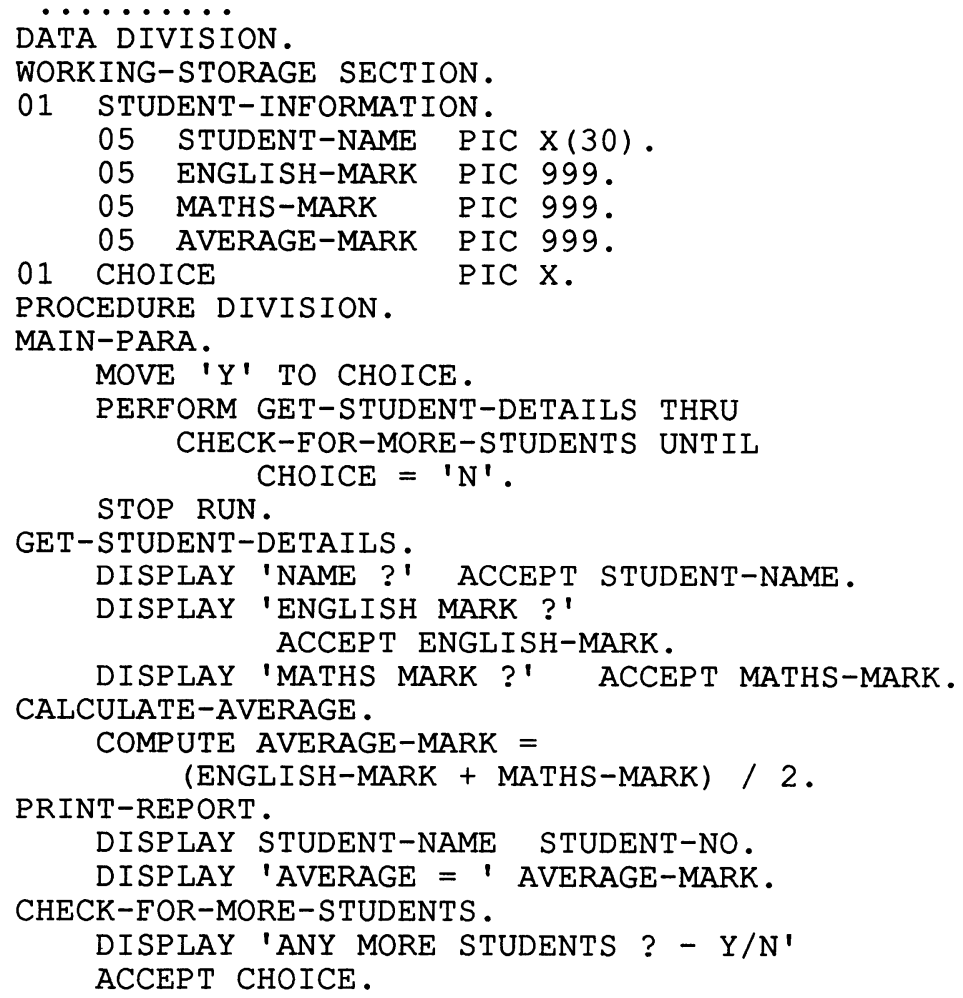

\section{Exercises}

1. Write a program which will ask for a worker's name, hours worked and hourly rate of pay, calculate his gross weekly wage, deduct tax at $30 \%$ and print a payslip showing the gross weekly wage, tax for the week and net weekly pay - then go on to do the same for the next employee and so on until the last employee (number 19) has been processed.

2. Write a program which will ask for a student's name and marks in three subjects, calculate the average and print a report - then ask if there are any more students on the list: carrying on to the next student if the response is ' $\mathrm{Y}$ ' - otherwise stopping. 